\title{
Diabetes mellitus and congestive heart failure: the prevalence of congestive heart failure in patients with and without diabetes in Poland
}

\author{
Waldemar Wierzba ${ }^{1}$, Waldemar Karnafel ${ }^{1}$, Andrzej Śliwczyński ${ }^{1,2}$, Jarosław Pinkas ${ }^{3}$, Mariusz Gujski ${ }^{4}$
}

\begin{abstract}
${ }^{1}$ Department of Public Health, University of Humanities and Economics, Lodz, Poland ${ }^{2}$ National Health Fund, Central Office, Warsaw, Poland

${ }^{3}$ School of Public Health, Centre of Postgraduate Medical Education, Warsaw, Poland ${ }^{4}$ Department of Prevention of Environmental Hazards and Allergology,

Medical University of Warsaw, Warsaw, Poland
\end{abstract}

Submitted: 2 February 2018; Accepted: 26 February 2018;

Online publication: 6 April 2018

Arch Med Sci 2021; 17 (3): 646-651

DOI: https://doi.org/10.5114/aoms.2018.74261

Copyright @ 2018 Termedia \& Banach

\begin{abstract}
Introduction: Diabetes mellitus is a systemic disease and has a negative effect on the cardiovascular system. This paper aimed to present a retrospective analysis of morbidity associated with heart failure in subgroups of patients with and without diabetes in Poland in 2012.

Material and methods: Data from the National Health Fund were used for the study. In general, 656,937 patients with heart failure, including 281,538 males and 375,354 females, were studied. In this population, additionally, 201,043 patients with heart failure (main diagnosis) and diabetes were studied, including 82,117 males and 118,926 females.

Results: The mean index of morbidity associated with heart failure in the whole subpopulation of diabetes patients was $9.03 \%$; $8.42 \%$ for males and $9.50 \%$ for females. Morbidity associated with heart failure in the population of patients diagnosed with diabetes in Poland in 2012 was seven times higher compared to morbidity associated with heart failure in non-diabetes patients. Morbidity associated with heart failure in females was significantly higher compared to morbidity in males in the whole population, in both the subpopulations of patients with and without diabetes.

Conclusions: Diabetes mellitus significantly increases risk of heart failure in both women and men. The risk is significantly high after the age of 60 years and higher in females.
\end{abstract}

Key words: diabetes mellitus, prevalence, morbidity, congestive heart failure.

\section{Introduction}

The incidence of congestive heart failure (CHF) is difficult to assess, because of various diagnostic criteria used in many publications [1]. The rates of incidence and morbidity associated with CHF may be underestimated [2]. Data regarding the incidence of CHF are usually taken from epidemiological studies conducted in highly developed countries [3, 4].

Type 2 diabetes mellitus (DM) is a risk factor of cardiovascular diseases $[5,6]$. The incidence of CHF in diabetic patients is not only underestimated, but it is also underdiagnosed, therefore more studies are needed $[7,8]$.

\author{
Corresponding author: \\ Waldemar Wierzba PhD \\ Department of Public Health \\ University \\ of Humanities \\ and Economics \\ 26 Sterlinga St \\ 90-212 Lodz, Poland \\ Phone: +48660196197 \\ E-mail:wwierzba@post.pl
}


Large epidemiological studies indicate that diabetes mellitus causes increased risk of $\operatorname{CHF}[9,10]$.

The paper aims to present retrospective analysis of prevalence of morbidity associated with heart failure in Poland based on reports of main diagnoses of CHF in two subpopulations: in patients diagnosed with diabetes and in non-diabetic patients. The study included all (100\%) reports presented in the database of the National Health Fund in the period between 1.01.2012 and 31.12.2012.

\section{Material and methods}

Health services in Poland are financed by the National Health Fund (NHF) based on the act and the regulations of the Minister of Health that result from this act [11-13]. Services are provided as part of outpatient and inpatient (hospital) treatment. The regulations of the NHF president determine the organisation, financing, and settlement of such services $[14,15]$. In order to perform an epidemiological analysis of data presented in NHF reports, selection with Structured Query Language (SQL) was performed. The number of PESEL (Common Electronic System for Citizens Evidence) was considered to be a unique patient identifier [16].

The NHF settles and pays for healthcare services provided by healthcare providers to patients. In the NHF database from the period between 1.01.2012 and 31.12.2012 there were reports regarding the number of patients with heart failure coded according to the International Statistical Classification of Diseases and Related Health Problems 10 ${ }^{\text {th }}$ Revision (ICD-10): 150 and $150.0-$ congestive heart failure; 150.1 - left ventricular heart failure; 150.9 - heart failure, unspecified.

In the NHF database in the period between 1.01 and 31.12.2012 reports associated with diabetes mellitus with the main diagnosis of "diabetes mellitus" with the following determinants were identified: E10.X - insulin-dependent diabetes mellitus; E11.X - non-insulin-dependent diabetes mellitus; E12.X - malnutrition-related diabetes mellitus; E13.X - other unspecified forms of diabetes mellitus; E14.X - unspecified diabetes mellitus or in this period a patient had a prescription for any medicinal products from the group A10.X (insulins), A10 B.X (oral anti-diabetic agents), and specialised (appropriate) diagnostic tests.

\section{Statistical analysis}

Date were obtained and prepared using the following tools: Structured Query Language and SAS software by SAS Institute. Student's t-test of independence was used. Differences were considered to be significant at the significance level of $95 \%$ $(p<0.05)$.

\section{Results}

The prevalence of CHF was compared between the diabetic and the general, non-diabetic population. Statistical data from the subpopulation of diabetic subjects and the subpopulation of non-diabetic patients were as follows: In general, in 2012 the Polish population, according to the data of the Central Statistical Office (GUS), included 38,533,789 people, including 18,651,441 males and 19,882,348 females [17]. In the period between 1 January and 31 December 2012 in total there were $2,227,453$ patients with diabetes (975,364 males and 1,252,089 females) in the analysed Polish population [18]. The general population without diabetes in 2012 included $36,306,336$ people, including $17,676,077$ males and 18,630,259 females [19].

Table I shows the numbers of people with the main diagnosis of congestive heart failure in Poland in 2012 taking into account the subpopulation of patients with diabetes and the subpopulation of non-diabetic patients, depending on the sex.

In 2012 in Poland 656,937 patients (281,538 males and 375,354 females) had the principal diagnosis of CHF. Of this population 201,043 people $(30.60 \%)$ subjects were diabetic $(82,117$ males and 118,926 females). The number of subjects with diagnosis of CHF without diabetes was 455,894, of whom 199,466 were male and 256,428 were female.

The average age of patients with $\mathrm{CHF}$ and with and without diabetes in Poland in 2012 was: in the male group with diabetes: $69.73 \pm 10.21$ ( $n=82$ 117); in the male group without diabetes: $69.27 \pm 12.97$ ( $n=199466)$; in the female group with diabetes: $74.42 \pm 9.41(n=118926)$; in the female group without diabetes: $74.89 \pm 12.33$ $(n=256$ 428).

Non-diabetic men were significantly younger than non-diabetic women $(p<0.001)$, and diabet-

Table I. Number of males and females with CHF with and without diabetes in Poland in 2012

\begin{tabular}{|lccc|}
\hline Number of patients with CHF & Male & Female & Total \\
\hline With diabetes & $82117(40.35 \%)$ & $118926(59.65 \%)$ & $201043(100 \%)$ \\
\hline Without diabetes & $199466(43.75 \%)$ & $256428(56.25 \%)$ & $455894(100 \%)$ \\
\hline Total & $281583(43.86 \%)$ & $375354(56.14 \%)$ & $656937(100 \%)$ \\
\hline
\end{tabular}


ic men were significantly younger than diabetic women $(p<0.001)$.

Table II lists the percentages of subjects with CHF with or without diabetes grouped by age.

Among non-diabetic subjects age CHF was observed in $77.40 \%$ of males and in $88.57 \%$ of females. In the diabetic population aged over 61 years CHF was present in $79.31 \%$ of males and in $91.61 \%$ of females.

Prevalence of $\mathrm{CHF}$ in the total Polish population calculated per 100,000 of the general population and percentage in relation to the total population in 2012 was: in the total male and female: $1704.83 / 100,000$ of the general population, i.e. $1.70 \%$ of population; in the male group: $1509.71 / 100,000$ of the general population, i.e. $1.51 \%$ of the population; in the female group: $1892.62 / 100,000$ of the general population, i.e. $1.89 \%$ of the population.

The prevalence of CHF in the total population was $1.70 \%$, of which $1.51 \%$ where males and $1.89 \%$ females - significantly higher than males $(p<0.001)$.

The prevalence of $\mathrm{CHF}$ for the whole diabetic population was $9.03 \%$ - males $8.42 \%$, females $9.50 \%$. For the non-diabetic population the prevalence was $1.26 \%$ - males $1.13 \%$, females $1.38 \%$.

The prevalence of CHF in both sexes was significantly higher in the diabetic population compared to non-diabetic $(p<0.001)$.
The prevalence of $\mathrm{CHF}$ in male diabetic patients was significantly lower than for the female population, both diabetic and non-diabetic $(p<0.001)$.

The prevalence of $\mathrm{CHF}$ in diabetic males was 7.45 times higher compared to non-diabetic males. The prevalence index of $\mathrm{CHF}$ in diabetic women was 6.9 times higher than in non-diabetic women.

Among 1000 subjects with diabetes in 2012 there were 90 subjects with diagnosis of CHF, while among 1000 non-diabetic subjects there were 12 subjects with diagnosis of CHF.

In the population of diabetic males over 60 years old in Poland in 2012 there were 595,235 people and in the equivalent population of women there were 923,052 [18]. In the subpopulation of diabetic males over 60 years old there were 65,127 subjects with heart CHF during that period, and 108,960 females [18]. The population of non-diabetic males in Poland in 2012 included 3,069,561 and for females 3,774,509 (Table III) [17, 18].

According to NHF data in 2012 in Poland there were 154,386 men over 60 years old without diabetes with principal diagnosis of $\mathrm{CHF}$ and 227,118 of women with this diagnosis [18].

The prevalence of CHF was at least twice as high in men and women with diabetes comparing with non-diabetic and was statistically significant $(p<0.001)$.

Table II. The number and percentage of CHFs in selected age groups in patients with and without diabetes in Poland in 2012, depending on the sex

\begin{tabular}{|lcccc|}
\hline Age ranges & \multicolumn{2}{c|}{$\begin{array}{c}\text { Patients with heart failure and without } \\
\text { diabetes (amount, percentage*) }\end{array}$} & \multicolumn{2}{c|}{$\begin{array}{c}\text { Patients with heart failure and with } \\
\text { diabetes (amount, percentage }\end{array}$} \\
\cline { 2 - 5 } & Male & Female & Male & Female \\
\hline Up to 30 years old & $n=1815$ & $n=1564$ & $n=90$ & $n=155$ \\
& $0.91 \%$ & $0.61 \%$ & $0.11 \%$ & $0.13 \%$ \\
\hline 30-50 years old & $n=9674$ & $n=5667$ & $n=1667$ & $n=939$ \\
& $4.85 \%$ & $2.21 \%$ & $2.03 \%$ & $0.79 \%$ \\
\hline 51-60 years old & $n=33,770$ & $n=22,079$ & $n=15,233$ & $n=8872$ \\
& $16.93 \%$ & $8.61 \%$ & $18.55 \%$ & $7.46 \%$ \\
\hline From the age of 61 years & $n=154,207$ & $n=227,118$ & $n=65,127$ & $n=108,960$ \\
& $77.31 \%$ & $88.57 \%$ & $79.31 \%$ & $91.62 \%$ \\
\hline Total & $n=199,466$ & $n=256,428$ & $n=82,117$ & $n=118,926$ \\
& $100.00 \%$ & $100.00 \%$ & $100.00 \%$ & $100.00 \%$ \\
\hline
\end{tabular}

${ }^{\star}$ The percentage rounded to 2 decimal places.

Table III. Prevalence of CHF in 60+ people in the subpopulations of males and females with and without diabetes in Poland in 2012

\begin{tabular}{|lcccc|}
\hline Subpopulation & \multicolumn{3}{c}{ Male } & Female \\
\cline { 2 - 5 } & Number of patients & Prevalence (\%) & Number of patients & Prevalence (\%) \\
\hline $\begin{array}{l}\text { Patients with diabetes } \\
\text { above 60 years of age }\end{array}$ & 595,235 & 10.94 & 923,052 & 11.80 \\
\hline $\begin{array}{l}\text { Patients without diabetes } \\
\text { over 60 years of age }\end{array}$ & $3,069,561$ & 5.02 & $3,774,509$ & 6.01 \\
\hline
\end{tabular}


In diabetic patients above 60 years old the prevalence of CHF was significantly higher compared to non-diabetics for both sexes $(p<0.001)$.

\section{Discussion}

Congestive heart failure is observed in $1 \%$ to $2 \%$ of the population $[20,21]$. The prevalence of $\mathrm{CHF}$ depends on the age of the population. In the USA Redfield et al. observed a CHF prevalence in the general population of $2.2 \%(95 \% \mathrm{Cl}: 1.6-2.8)$, and in the age group $45-54$ years it was $0.7 \%$, while the $75+$ years age group reached $8.4 \%$ [22].

Heart failure often coexists with other diseases, such as chronic bronchitis, it is one of the main causes of hospitalisation in the USA. Congestive heart failure accounts for approximately 277,000 deaths annually in the United States and approximately $34 \%$ of cardiovascular-related deaths. One in nine deaths in the United States involves heart failure [23].

In a study by Owan et al. from Mayo Clinic hospitals the prevalence of $\mathrm{CHF}$ in the general population was as follows: age group 55-64 years $-1 \%$; age group 65-74 years - 3\%; age group 75-84 years $-7 \%$; and in the age group above 85 years - 10\% [24].

Shah et al. presented the results of a prospective study lasting 5.5 years of $1,887,062$ non-diabetic subjects and 34,198 subjects with type 2 diabetes mellitus demonstrating a prevalence of $\mathrm{CHF}$ twice as frequent in the population with diabetes mellitus type 2 [25].

According to Rydén et al. increased incidence of CHF in patients with diabetes mellitus type 2 is associated with chronic arterial hypertension, chronic hyperglycaemia, microangiopathy, and other abnormalities [26, 27].

Gottdiener et al. showed that the incidence of CHF in diabetic patients was twice as high as in non-diabetic patients [10]. Similarly, in a study by the Kaiser Permanente Centre for Health Research, Nichols et al. showed that the prevalence associated with CHF in diabetic patients was more than twice as high as in non-diabetic patients [28].

In another study Nichols et al. showed in 2004 that among 1000 patients with type 2 diabetes there were 25-30 cases of CHF per year more compared to a group of 1000 patients without diabetes type 2 [9].

In the Antihypertensive and Lipid-Lowering Treatment to Prevent Heart Attack trial (ALLHAT) Davis et al. demonstrated that there was a significant correlation between the presence of diabetes and heart failure. In diabetic patients hospitalisations and deaths were observed significantly more frequently than in a group of subjects without diabetes and concomitant heart failure [29].
According to From et al. diabetes is a significant risk factor for heart failure, which does not depend on coronary artery disease, arterial hypertension, and other potential confounding factors [30].

In Poland, Rywik et al. stated that in 2011 the number of people with CHF was approximately 600,000 [31].

So far, there have not been any comparative epidemiological studies on the incidence of heart failure in people with and without diabetes conducted in Poland.

In our studies in Poland in 2012 the prevalence of $\mathrm{CHF}$ in both sexes was $1.7 \%$, including $1.51 \%$ in men and $1.89 \%$ in women, based on the NHF data.

The prevalence of $\mathrm{CHF}$ in diabetic patients was $9.03 \%$ for both sexes, $8.42 \%$ for males, and $9.50 \%$ for females. The prevalence of CHF in non-diabetic patients was $1.25 \%$ for both sexes, $1.13 \%$ for males, and $1.38 \%$ for females. The prevalence of CHF in diabetic subjects in Poland in 2012 was seven times higher than in non-diabetics.

In our study there was a higher prevalence of CHF among women compared to men, similarly as in studies by such researchers as Gustafsson et al. [32].

In the population of men over 60 years old without diabetes the prevalence of heart failure was $5.02 \%$, and among women it was $6.01 \%$. On the other hand, in the population of $60+$ men with diabetes the prevalence of CHF was $10.94 \%$, and among women it was as high as $11.80 \%$.

The prevalence of heart failure in people above the age of 60 years with diabetes was approximately twice as high as in non-diabetic patients, which was also demonstrated by Nichols et al. and Gottdiener et al. $[9,10]$. In the papers of the authors mentioned above the mean age of patients was above 60 years.

Our studies included the whole population of Poland in the period between 1.01.2012 and 31.12.2012.

The studies by Nichols et al. and Gottdiener et al. included patients with type 2 diabetes mellitus, whereas our studies included patients with all types of diabetes, and this may have been associated with differences in prevalence of $\mathrm{CHF}$ that could be observed.

In our studies in 2012 among 1000 patients with diabetes there were 78 patients with heart failure more compared to a group of 1000 people without diabetes.

Among the causes of this phenomenon is the poor metabolic control of diabetes, the treatment of which worsens with the duration of diabetes, and which is an important risk factor for the development of cardiovascular diseases [33].

In patients with diabetes, lipid disorders are common, which are also a very important risk fac- 
tor for the development of cardiovascular diseases. The Polish authors showed that the average occurrence of familial hypercholesterolaemia in Poland is 404/100,000 of the general population. Unfortunately, there are no routine tests of familial hypercholesterolaemia (screening) in people under 18 years old [34].

Our studies had limitations and therefore it was not possible to assess the most important risk factors of heart failure, such as the presence of coronary heart disease, arterial hypertension, obesity, lipid abnormalities, duration of diabetes, and compensation of diabetes metabolism, and such factors are emphasised by such authors as Komanduri et al. [21] or Rydén et al. [26, 27].

In conclusion, studies conducted showed that diabetes mellitus significantly increased the risk of heart failure both in women and men. The risk is significantly high after the age of 60 years and significantly higher in females, based on the following information: The prevalence of $\mathrm{CHF}$ in Poland in 2012 in diabetes patients was 1.70\% for both sexes, $1.51 \%$ for males, and $1.89 \%$ for females, based on the NHF data. More than 30\% of all cases of $\mathrm{CHF}$ were observed in patients diagnosed with diabetes. The prevalence of $\mathrm{CHF}$ in the population of patients diagnosed with diabetes in Poland in 2012 was seven times higher compared to morbidity associated with CHF in non-diabetic patients. In men with diabetes it was $8.42 \%$, and in women it was $9.50 \%$. In non-diabetic patients the prevalence of $\mathrm{CHF}$ was respectively lower and was: $1.13 \%$ in males and $1.38 \%$ in females. The prevalence of $\mathrm{CHF}$ in females was significantly higher compared to males in the whole population, in both the subpopulations of patients with and without diabetes. The prevalence of $\mathrm{CHF}$ in the population over 60 years old with diabetes was more than twice as high in men and almost twice as high in women as in non-diabetic patients. In more than $77 \%$, heart failure was present at the age above 60 years.

\section{Conflict of interest}

The authors declare no conflict of interest.

\section{References}

1. Massie BM, Shah NB. The heart failure epidemic: magnitude of the problem and potential mitigating approaches. Curr Opin Cardiol 1996; 11: 221-6.

2. McKee PA, Castelli WP, McNamara PM, Kannel WB. The natural history of congestive heart failure: the Framingham study. N Engl J Med 1971; 285: 1441-6.

3. Eriksson H. Heart failure: a growing public health problem. J Int Med 1995; 237: 135-1.

4. Kannel WB, Belanger AJ. Epidemiology of heart failure. Am Heart J 1991; 121: 951-7.

5. Sarwar N, Gao P, Seshasai SR, et al. Diabetes mellitus, fasting blood glucose concentration, and risk of vascu- lar disease: a collaborative meta-analysis of 102 prospective studies. Lancet 2010; 375: 2215-22.

6. Beckman JA, Creager MA, Libby P. Diabetes and atherosclerosis: epidemiology, pathophysiology, and management. JAMA 2002; 287: 2570-81.

7. Marx N. Heart failure and diabetes - underestimated, underdiagnosed and poorly understood: a call for action. Diab Vasc Dis Res 2017; 14: 67-8.

8. Grant PJ. Myocardial dysfunction in diabetes: another epidemic? Diab Vasc Dis Res 2016; 13: 319-20.

9. Nichols GA, Gullion CM, Koro CE, et al. The incidence of congestive heart failure in type 2 diabetes: an update. Diabetes Care 2004; 27: 1879-84.

10. Gottdiener JS, Arnold AM, Aurigemma GP, et al. Predictors of congestive heart failure in the elderly: the Cardiovascular Health Study. J Am Coll Cardiol 2000; 35: 1628-37.

11. Act of 27.08.2004 on health care services financed from public funds. (Journal of Laws 2008, no. 164, item 1027, as amended).

12. Regulation of the Minister of Health of 11 January 2010 amending the regulation on guaranteed benefits in the field of health programs (Journal of Laws 2010 No. 05, item 29, as amended).

13. Regulation of the Minister of Health of 2 March 2010 amending the regulation on guaranteed benefits in the field of hospital treatment (Journal of Laws of 2010, No. 30 , item 157, as amended).

14. Order No. 101/2007/DGL of the President of the National Health Fund dated 5 November 2007 amending the Order on the adoption of "Detailed information materials on proceedings concerning the conclusion of healthcare contracts and the implementation and financing of healthcare contracts Type: hospital treatment".

15. Order No. 36/2008/DGL of the President of the National Health Fund of 19 June 2008 on defining the conditions for concluding and implementing contracts such as hospital treatment in the field of therapeutic health programs.

16. PESEL. Available from: http://www.msw.gov.pl/portal/ pl/381/32/PESEL.html. Accessed July 10, 2017. Polish.

17. Central Statistical Office. Size and structure of population and vital statistics in Poland in 2012. http://stat.gov. pl/obszary-tematyczne/ludnosc/ludnosc/ludnosc-stani-struktura-ludnosci-oraz-ruch-naturalny-w-przekrojuterytorialnym-stan-w-dniu-31-xii-2012-r-,6,11.html. Accessed July 10, 2017.

18. Czeleko T, Śliwczyński A, Dziemidok P, et al. Known diabetes mellitus in the year 2012 as registered by the National Health Fund for Poland in urban and rural populations [Polish]. Metab Med 2017; 21: 16-23.

19. Wierzba W, Pinkas J, Karnafel W, Dziemidok P, Jawien A, Śliwczynski A. Evaluation of the incidence of aortic aneurysms in patients with and without diabetes in Poland in 2012 based on the database of the National Health Fund. Arch Med Sci 2019; 15: 607-12.

20. Mendez GF, Cowie MR. The epidemiological features of heart failure in developing countries: a review of the literature. Int J Cardiol 2001; 80: 213-9.

21. Komanduri S, Jadhao Y, Guduru SS, et al. Prevalence and risk factors of heart failure in the USA: NHANES 20132014 epidemiological follow-up study. J Community Hosp Intern Med Perspect 2017; 7: 15-20.

22. Redfield MM, Jacobsen SJ, Burnett JC Jr, et al. Burden of systolic and diastolic ventricular dysfunction in the community: appreciating the scope of the heart failure epidemic. JAMA 2003; 289: 194-202.

23. Pierre-Louis B, Rodriques S, Gorospe V, et al. Clinical factors associated with early readmission among acutely 
decompensated heart failure patients. Arch Med Sci 2016; 12: 538-45.

24. Owan TE, Hodge DO, Herges RM, et al. Trends in prevalence and outcome of heart failure with preserved ejection fraction. N Engl J Med 2006; 355: 251-9.

25. Shah AD, Langenberg C, Rapsomaniki E, et al. Type 2 diabetes and incidence of cardiovascular diseases: a cohort study in 1.9 million people. Lancet Diabetes Endocrinol 2015; 3: 105-13.

26. Rydén L, Grant PJ, Anker SD, et al. ESC Guidelines on diabetes, pre-diabetes, and cardiovascular diseases developed in collaboration with the EASD: the Task Force on diabetes, pre-diabetes, and cardiovascular diseases of the European Society of Cardiology (ESC) and developed in collaboration with the European Association for the Study of Diabetes (EASD). Eur Heart J 2013; 34: 3035-87.

27. Rydén L, Grant PJ, Anker SD, et al. ESC Guidelines on diabetes, pre-diabetes, and cardiovascular diseases developed in collaboration with the EASD - Summary: The Task Force on diabetes, pre-diabetes, and cardiovascular diseases of the European Society of Cardiology (ESC) and developed in collaboration with the European Association for the Study of Diabetes (EASD). Diab Vasc Dis Res 2014; 11: 133-73.

28. Nichols GA, Hillier TA, Erbey JR, et al. Congestive heart failure in type 2 diabetes: prevalence, incidence, and risk factors. Diabetes Care 2001; 24: 1614-9.

29. Davis BR, Piller LB, Cutler JA, et al. Role of diuretics in the prevention of heart failure. The antihypertensive and lipid-lowering treatment to prevent heart attack trial. Circulation 2006; 113: 2201-10.

30. From AM, Leibson CL, Bursi F, et al. Diabetes in heart failure: prevalence and impact on outcome in the population. Am J Med 2006; 119: 591-9.

31. Rywik TM, Kołodziej P, Targoński R, et al. Characteristics of the heart failure population in Poland: ZOPAN, a multicentre national program. Kardiol Pol 2011; 69: 24-31.

32. Gustafsson I, Brendorp B. Seibaek M, et al. Influence of diabetes and diabetes-gender interaction on the risk of death in patients hospitalized with congestive heart failure. J Am Coll Cardiol 2004; 43: 771-7.

33. Stefanowicz A, Mysliwiec M, Adamkiewicz-Drozynska E. Parental knowledge and metabolic control of children and young adults with type 1 diabetes. Arch Med Sci 2018; 14: 52-9.

34. Pajak A, Szafraniec K, Polak M, et al. Prevalence of familial hypercholesterolemia: a meta-analysis of six large, observational, population-based studies in Poland. Arch Med Sci 2016; 12: 687-96. 